\title{
DEVELOPING STAKEHOLDER ARCHETYPES FOR ENHANCED LANDFILL MINING
}

\author{
Paul Einhäupl 1,2, , Karel Van Acker ${ }^{1,3}$, Niclas Svensson ${ }^{4}$ and Steven Van Passel ${ }^{2}$ \\ ${ }^{1}$ Katholieke Universiteit Leuven - Materials Engineering, Faculty of Engineering Sciences Kasteelpark, Arenberg 44, Leuven 3001, Bel- \\ gium \\ 2 Universiteit Antwerpen - Engineering Management, Faculty of Business and Economics, Prinsstraat \\ 13 Room: B.122, Antwerpen 2000, Belgium \\ ${ }^{3}$ Katholieke Universiteit Leuven - Research Centre for Economics and Corporate Sustainability (CEDON), Leuven, Flanders, Belgium \\ ${ }^{4}$ Linköping University - Department of Management and Engineering, Linkoping, Sweden
}

Article Info:

Received:

29 April 2019

Revised:

10 December 2019

Accepted:

13 December 2019

Available online:

23 December 2019

Keywords:

Stakeholder

Archetypes

ELFM

Societal Assessment

Remo Landfill

Circular Economy

Semi-structured interviews

\begin{abstract}
Understanding the perspectives of different stakeholders on emerging technological concepts is an important step towards their implementation. Enhanced Landfill Mining (ELFM) is one of these emerging concepts. It aims at valorizing past waste streams to higher added values in a sustainable manner. Yet, assessment of ELFM mainly focusses on environmental and private economic issues, and societal impacts are rarely analyzed. This study uses semi-structured interviews to build understanding for different ELFM practitioners and researchers and develops five stakeholder archetypes for ELFM implementation: the Engaged Citizen, the Entrepreneur, the Technology Enthusiast, the Visionary and the Skeptic. The archetypes outline major differences in approaching ELFM implementation. The stakeholder perceptions are put into context with existing literature, and implications for ELFM implementation and future research are discussed. Results show that differences in regulatory changes and technology choices are affected by different stakeholder perspectives and more research is needed to balance inner- and inter-dimensional conflicts of ELFM's sustainability. The developed archetypes can especially be helpful when evaluating social impacts, whose perception often depends on opinion and is difficult to quantify.
\end{abstract}

\section{INTRODUCTION}

Growing pressure on environmental change has dominated the recent public discussion on climate-related issues. Yet, regulatory measures to reduce $\mathrm{CO}_{2}$ emissions, for example, are not always perceived as fair and effective by all members of society. This can be seen in the recent 'Gilet Jaunes' movement in France, for which positive environmental change is perceived as conflicting with social needs (Amjahid and Raether, 2018). Nonetheless, the effective management of natural resources (NRM) plays an important role in avoiding future climate impacts. Making it compatible with social and economic needs is therefore essential for its implementation. NRM affects societal, environmental and economic change, connecting all dimensions of sustainability. The importance of NRM is reflected in the Paris Agreement, where signatories are obliged to build up the resilience of socio-economic and environmental systems through NRM (UN, 2016). To tackle this challenge, it is not only important to advance towards a renewable energy system and rethink major production processes. It also calls for new technologies and material sources, to integrate secondary raw materials into a circular economy. To do so, the European Union has developed an Action Plan for Circular Economy, covering elements of production, consumption, and waste management (EC, 2015). As implemented in the EU Landfill Directive, the Action Plan also calls for a waste hierarchy and focusses on the prevention and recycling of waste, integrating current streams into resource management (EC, 2015, 1999). However, past waste streams are mostly being ignored and have traditionally been landfilled (Krook et al., 2012), and with them valuable materials and resources.

Growing market and environmental pressures have led to the development of a rather new concept: Enhanced Landfill Mining (ELFM). ELFM aims to add value to past urban waste streams as materials (Waste-to-Material, WtM) and energy (Waste-to-Energy, WtE) using innovative technology in an integrated, environmentally and societally sound way (Jones et al., 2013). The concept originated from remediation projects and has since shifted to the creation 
of higher added values (e.g. hydrogen) (Krook et al., 2012, Jones et al., 2013). Potentially, ELFM could lead to the mitigation of primary resource production and therefore generate positive environmental effects (Danthurebandara et al., 2015a; Jain et al., 2014). Its economic performance, on the other hand, is still unclear. High investment and processing costs hinder ELFM implementation, despite environmental gains (Hermann et al., 2016a; Kieckhäfer et al., 2017). Societal factors are rarely considered in ELFM research or generalized to an extent where impacts an effects become entangled, often through monetization, making it difficult to draw conclusions (Damigos et al., 2015; Van Passel et al., 2013).

\section{AIM AND SCOPE}

A limited current knowledge base (Krook et al., 2018), and a lack of industrial experience emphasizes the need for research in the field. Krook, Svensson, and Eklund (2012) conclude further investigations on stakeholder perceptions including societal actors are "essential for understanding the capacity of technology and conditions for realization" of ELFM. While current studies usually focus on environmental risks or economic assessments, it remains unclear, how different stakeholders approach ELFM and how different perceptions affect ELFM implementation. The aim of the paper is to make differences and similarities of various stakeholders' perspectives on ELFM explicit. The findings are structured through the development of stakeholder archetypes. These archetypes provide a basis for ELFM research to integrate societal factors and enhance assessment methods as well as the scientific discussion on ELFM by integrating different opinions rather than a seeming objectivity. This is especially important considering the quantification of societal impacts, as results can be biased to some extent not only by the chosen method but also by the perspective taken by the assessor. The archetypes further provide information to different stakeholders involved in ELFM and can help nurture each other's understanding to avoid societal conflicts along the road of implementation. The developed archetypes can be used as educational material to explain and better understand inner- and interdimensional conflicts of sustainability when implementing new technology concepts. They are an easyto-use tool to show differences in knowledge distributions amongst stakeholders and can provide valuable insights for policymakers. They give industry actors the opportunity to develop a better understanding of partners and market conditions and can help to avoid fears and worries in the general population.

The scope of this study is limited to ELFM implementation and conclusions to other industry sectors are not drawn. It focusses on a Belgium case at the Remo landfill in Flanders. The Remo case provides a well researched scientific basis to reasonably interpret results and a high degree of stakeholder involvement (Bosmans et al., 2013; Danthurebandara et al., 2013; Quaghebeur et al., 2010). It comprises an area of about 160 hectares dedicated to landfilling and stores about 16.5 million tons of municipal solid (MSW) and industrial (IW) waste. Leachate protec- tion, as well as a gas collection system, are installed at the facilities. Within the "Closing the Circle" (CtC) project, initiated by the operators, ELFM operations are planned in the near future (Geysen, 2017; Group Machiels, 2018; Quaghebeur et al., 2013). Additionally, neighboring community members have formed a citizen initiative called DeLocals. Their goal is to understand the ELFM operations at Remo and distribute information about developments, accomplishments as well as problems to relevant stakeholders (Ballard et al., 2018). The study considers perspectives on landfilling in general, ELMF implementation, the different dimensions of sustainability in ELFM as well as regulatory issues. Misconceptions and knowledge gaps within stakeholder groups are discussed as well as implications for ELFM implementation. The study uses interviews for assessment and considers a brought range of stakeholders, including institutional, industrial, scientific and communal actors.

\section{MATERIALS \& METHOD}

To develop the different stakeholder archetypes, semi-structured interviews were conducted. To do so, an interview guide was developed based on the relevant literature. The stakeholder selection process was based on an extended quadruple-helix (QH) framework (Arnkil et al., 2010; Kolehmainen et al., 2016). The analysis was based on the general inductive approach by Thomas (2006). Interviews were taken in person or on the phone with a total of 13 interviewees. The interviews were analyzed using a general inductive approach (Thomas, 2006) and from the findings, the stakeholder archetypes were developed. It is important to stress the qualitative nature of the study. Through in-depth interviews we intent to derive what motivates and drives different stakeholders with regards to their stakeholder classes of a specific ELFM case, i.e. the Remo landfill. This approach helps to avoid hypothetical biases as well as an over-representation of one stakeholder group. However, a restricted pool of potential interviewees due to the case specification, and additional temporal constraints limit the number of interviews and therefore the statistical representativeness of the study. Nonetheless, as the Remo case is of scientific interest, we believe this research adds a missing part and provides a basis for the future investigation of societal impacts.

\subsection{The Interview Guide}

From an initial review of the relevant literature, five major themes of scientific interest were identified. Assessed parameters and derived research needs were carefully analyzed. The themes included (i) "perspectives on landfills and their management" (e.g. Krook, Svensson, and Eklund 2012), (ii) "economic drivers and barriers for ELFM" (e.g. Danthurebandara et al. 2015; Frändegård, Krook, and Svensson 2015), (iii) "environmental benefits and risks of ELFM" (e.g. Gusca, Fainzilbergs, and Muizniece 2015; Laner et al. 2016), (iv) "societal challenges for ELFM implementation" (e.g. Van Passel et al. 2013; Lederer, Laner, and Fellner 2014), and (v) "the role and responsibilities of institutions and other stakeholders involved in ELFM activ- 
ities" (e.g. Krook, Svensson, and Eklund 2012; Johansson 2016). While the first theme (i) was chosen to identify the general approach of participants to landfills and ELFM, the second, third and fourth themes (ii-iv) aim at analyzing the perceived sustainability of ELFM. The last theme (v) was chosen to investigate how different stakeholders are involved in ELFM projects and where they are able to influence processes along realization. The interview guide can be found in the Annex to this study.

\subsection{The Extended Quadruple-helix Framework}

The Quadruple-Helix (QH) framework is often used in the context of new technological development and distinguishes between various actors at different points of innovation processes. It aims to capture multiple and reciprocal relations between involved stakeholders (Arnkil et al., 2010; Kolehmainen et al., 2016). It consists of four major strands: The institutional, the scientific, the societal and the industrial strand. The industrial strand was further subclassified along the value-creation-chain of ELFM. This resulted in subclasses: operators, technology providers, and buyers. Additionally, attributes were added to the $\mathrm{QH}$ framework to further differentiate certain properties of the interviewees. The attributes included (i) level of operation, i.e. local, regional, federal or supranational, (ii) level of case-involvement and (iii) level of impact on overall ELFM implementation, both differentiated between high, moderate, and low, first evaluated by the researchers and consequently adapted through new findings from the interviews, as well as the stakeholder's (iv) organizational type, distinguishing governmental (gov.), non-governmental (n-gov.) or private (p) organizations. A schematic representation of the extended $\mathrm{QH}$ framework can be seen in Figure 1.

\subsection{Analysis}

The general inductive approach was used to derive concepts, models, and structures from the raw interview data. The unit of analysis used was "concepts"(Corbin and Strauss, 1990). In this study, a concept could comprise only one word or several sentences. The analysis was done in three main steps. First, the raw textual data was condensed into a brief summary format. In the second step, the summary findings were used to establish clear links and relations between various actors and concepts expressed during the interviews. Consequentially, a theoretical framework about the underlying structure of the research findings was developed, i.e. the stakeholder archetypes (Thomas, 2006). To put the general inductive approach into practice, concepts were coded according to the categories of the interview guide, providing a priori-coding and using QSR International's NVivo 11 software. Similar statements were joined into one coding category and related interviewees connected to the statements to derive clear differences between actors and concepts. Overlapping coding was allowed, opening up the possibility of one concept being assigned to several coding categories, hinting to links between them. Consequentially, concepts, interlinked through stakeholder class and/or content, were grouped and structured in a sensible manner by tabulating them and develop the stakeholder archetypes.

\subsection{Stakeholder Selection}

The study includes three actors from institutions and one scientific actor from a university. To include the societal community of the QH framework, three interviews were held with neighbors from the surrounding communities of the Remo landfill. The extended industrial strand included two managers from the operating company, two technology providers, and one technology incubator. The incubator was chosen to represent buyers of ELFM products. Since operations at the Remo site have not started yet, finding real buyers was not possible. Focusing also on waste management and operating in a similar region, the technology incubator was chosen as a proxy-representative for this stakeholder class. An overview of all participants can be found in Table 1.

\section{RESULTS}

The results are structured in two basic parts. First, the descriptive summary of the interviews is presented. Its purpose is to provide a more detailed overview of the different stakeholder perspectives and transparency to make results reproducible. The second part presents the developed stakeholder archetypes.

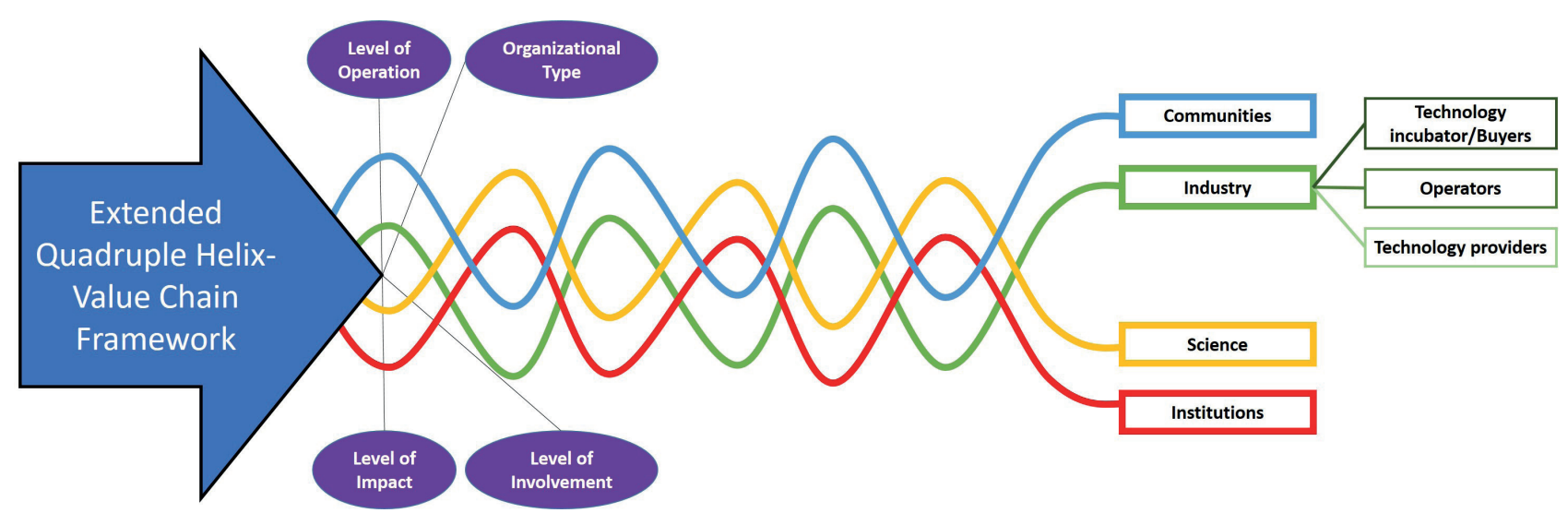

FIGURE 1: The Figure shows the extended quadruple-helix framework including sub-classes and attributes. 
TABLE 1: Table 1 shows the interviewees sorted by stakeholder class.

\begin{tabular}{|c|c|c|c|c|}
\hline $\mathrm{QH} /$ value chain-Class & Stakeholder & Attributes & No. & \\
\hline \multirow[t]{2}{*}{ Community members } & & & & 3 \\
\hline & De Locals & $\begin{array}{l}\text { Non-governmental } \\
\text { Local } \\
\text { Medium/high influence } \\
\text { Low/medium impact }\end{array}$ & 3 & \\
\hline \multirow[t]{4}{*}{ Institutional actors } & & & & 4 \\
\hline & Government & $\begin{array}{l}\text { Governmental } \\
\text { Local } \\
\text { High influence } \\
\text { Low impact }\end{array}$ & 1 & \\
\hline & Waste Agency & $\begin{array}{l}\text { Governmental } \\
\text { Regional } \\
\text { High influence } \\
\text { Medium impact }\end{array}$ & 2 & \\
\hline & European Commission & $\begin{array}{l}\text { Governmental Supranational } \\
\text { Medium influence } \\
\text { High impact }\end{array}$ & 1 & \\
\hline \multirow[t]{2}{*}{ Scientific actors } & & & & 1 \\
\hline & Researcher & $\begin{array}{l}\text { Non-governmental } \\
\text { Supranational } \\
\text { Low/medium influence } \\
\text { Medium/high impact }\end{array}$ & 1 & \\
\hline \multirow[t]{4}{*}{ Industrial actors } & & & & 5 \\
\hline & Operators & $\begin{array}{l}\text { Private } \\
\text { Supranational } \\
\text { High influence } \\
\text { Medium/high impact }\end{array}$ & 2 & \\
\hline & Technology providers & $\begin{array}{l}\text { Private } \\
\text { Supranational } \\
\text { Medium influence } \\
\text { Medium impact }\end{array}$ & 2 & \\
\hline & Technology incubator & $\begin{array}{l}\text { Private } \\
\text { Regional } \\
\text { Low influence } \\
\text { Medium impact }\end{array}$ & 1 & \\
\hline Total & & & & 13 \\
\hline
\end{tabular}

\subsection{Descriptive summary}

The descriptive summary entails the main concepts addressed by the stakeholders during the interviews. As ELFM is a relatively young field of research and lacks the assessment of societal factors, this descriptive part should help the reader understand and comprehend the findings, and could provide a basis for future research. The first subsection, Approach to landfills, describes how stakeholders perceive the functions and safety of the Remo landfill, as well as advantages and disadvantages. The second subsection, Concept, and attitude towards ELFM, describes how stakeholders approach ELFM in general and what differences they perceive in the concept. The next three subsections, economic drivers and barriers, environmental risks and benefits and societal challenges for ELFM, treat perceptions about the sustainability of ELFM. The last subsection, Key Actors of ELFM, describes who the different stakeholders perceive as playing the most influential role in ELFM implementation.

\subsubsection{Approach to Landfills}

All stakeholders perceive a temporary storage function of landfills. Yet, landfilling is considered the least favorable waste treatment option, but deemed necessary throughout most interviewees. The operating company emphasizes the offered service of waste disposal, whereas the scientific side also mentioned landfills as a source of pollution and, like the technology incubator, a land occupant. Institutional participants make an explicit distinction between "dumpsites" that pre-date the European Landfill Directive from 1999 and "landfills" that comply with it.

Technology providers perceived advantages of landfilling waste over incineration. They explained the storage function of landfills with a lack of technologies to handle certain waste streams in the past and made it clear that significant amounts of waste would still be landfilled in the future, passing the problems on to the next generation

All participants accentuated that a properly operated landfill under current legislation could be considered safe, but older landfills are often perceived as less safe. Nevertheless, distinctions in perceptions lay in the details: The landfill operators made a distinction of "very old landfills" justified by changes in landfilled waste streams: "...when you go back in the past there are not that many risky waste streams..." This is coherent with the experiences of institutional participants stating most landfills are in better conditions than estimated, and the expected toxic "time-bombs seem not to be a reality after all". Additionally, the institu- 
tional side stressed that changing circumstances, due to changes in climatic conditions, can affect the safety of a landfill, for example through higher flood risks. Flooding a landfill could potentially endanger groundwater reservoirs and the stability of landfills through soil movements. The technology incubator criticized illegal waste dumping as a major risk and perceived a lack of control mechanisms for waste disposal.

Perceived advantages of landfills are the potential for resource recovery and the removal of waste from the local communities. The institutional participants also stated an advantage in being able to control the process of waste disposal.

Perceived disadvantages, on the other hand, were approached differently. While all stakeholders mentioned a suboptimal use of land and environmental risks, operators also mentioned the installation of additional security measures against wildlife as well as risks coming directly from ongoing operations. Local communities further perceived risk for human health coming from toxic materials (e.g. mercury or asbestos), whereas the researcher stated a disadvantage of industrial landfills often containing toxic materials, in combination with a lack of control mechanisms.

Concerning the Remo site, all stakeholders had positive associations, although opposing groups to the project from local communities and politics were also mentioned. The operators were described as "thinking in a modern way" or "courageous". Problems from the past are perceived as mostly resolved and communication between stakeholders has improved. The most critique about the site came from operators themselves, where the need for optimization of processes and technology was expressed. Negative associations from local community members and the institutional side were mainly towards landfills in general, coming from experiences pre-dating the EU Landfill Directive. Table 2 gives an overview of the results from this section.

\subsubsection{Concept and Attitude Towards ELFM}

The concept of ELFM and distinctions to traditional LFM were perceived differently between stakeholders. Yet, all stakeholders stated a mostly positive attitude towards ELFM.

For operators, ELFM should be carried out as a private business activity. The main distinction of traditional LFM was presented by involving stakeholders. Local community members and institutional participants put a focus on material recovery using high-level recycling and sorting technologies, whereas the institutional side even expanded the concept of ELFM to Enhanced Landfill Management and Mining (ELFM ${ }^{2}$ ), including managing an interimuse phase of landfills until mining activities would start. The local government has developed a code of conduct to communicate safety issues with the operators and police forces and is driven towards ELFM mainly for environmental reasons. Technology providers, in contrast to the operators, perceive ELFM as an environmental clean-up activity using advanced technology, where thermal treatment of waste could be an end-of-pipe solution, minimizing disposal costs for ELFM. The technology incubator focussed on maximizing the added value of materials, making reuse and recycling strategies a primary objective. Institutions and operators are convinced most landfills will be mined in the future, while it cannot be considered an option categorically. The scientific participant emphasized the importance of ELFM having almost no discharge flow and described it as an (economically) "risky recycling activity".

Operators are actively engaging in ELFM for profitorientated reasons with environmental "spillovers", given a "clear, positive, net balance". Other stakeholders are motivated to engage in ELFM for environmental reasons. Nevertheless, ELFM should be able to stand economically independent from an institutional and industrial point of view. Table 3 gives an overview of the results from this section.

\subsubsection{Perceived Sustainability}

The perceived sustainability of ELFM is derived from the themes (ii), (iii) and (iv). Throughout the interviews, participants were asked to describe economic drivers and barriers, environmental risks and benefits and societal challenges. While economic drivers and barriers were

TABLE 2: Table 2 summarizes the Approach to Landfills.

\begin{tabular}{|c|c|c|c|}
\hline \multirow{2}{*}{$\mathrm{QH} /$ value chain-Class } & \multirow{2}{*}{ Stakeholder } & \multicolumn{2}{|c|}{ Approach to landfills } \\
\hline & & Specific Beliefs & Common Beliefs \\
\hline Community members & De Locals & $\begin{array}{l}\text { - The risk for human health } \\
\text { - Problems with odor }\end{array}$ & $\begin{array}{l}\text { - Landfills function as a temporary storage } \\
\text { - Mostly positive associations with Remo site }\end{array}$ \\
\hline \multirow[t]{3}{*}{ Institutional Actors } & Waste Agency & $\begin{array}{l}\text { - Fewer risks than expected } \\
\text { - Flood risks }\end{array}$ & \multirow{7}{*}{$\begin{array}{l}\text { Advantages: Potential for material recovery and } \\
\text { waste removal } \\
\text { Disadvantages: Suboptimal use of land, envi- } \\
\text { ronmental risks }\end{array}$} \\
\hline & European Union & - Distinction between "dumpsites" and landfills & \\
\hline & Local Government & $\begin{array}{l}\text { - Focus on permitting activities } \\
\text { - Problems with operators in the past, followed by } \\
\text { positive change }\end{array}$ & \\
\hline Scientific Actors & Researcher & - Source of pollution & \\
\hline \multirow[t]{3}{*}{ Business Actors } & Operators & $\begin{array}{l}\text { - Waste disposal service } \\
\text { - Process optimization needed }\end{array}$ & \\
\hline & Technology Provider & $\begin{array}{l}\text { - Long term risks are uncertain } \\
\text { - Landfilling is preferred over incineration }\end{array}$ & \\
\hline & Technology incubator & $\begin{array}{l}\text { - Landfills as land occupant } \\
\text { - Illegal waste dumping }\end{array}$ & \\
\hline
\end{tabular}


TABLE 3: Table 3 summarizes the Concept and Attitude Towards ELFM.

\begin{tabular}{|c|c|c|c|}
\hline \multirow{2}{*}{ QH/value chain-Class } & \multirow{2}{*}{ Stakeholder } & \multicolumn{2}{|c|}{ Concept and attitude towards ELFM } \\
\hline & & Specific Beliefs & Common Beliefs \\
\hline Community members & De Locals & $\begin{array}{l}\text { Focus on material recovery and advanced } \\
\text { recycling technology } \\
\text { - Approach from an environmental perspective }\end{array}$ & \multirow[t]{8}{*}{$\begin{array}{l}\text { - Positive attitude towards ELFM } \\
\text { - Not every landfill is suitable for ELFM }\end{array}$} \\
\hline \multirow[t]{3}{*}{ Institutional Actors } & Waste Agency & $\begin{array}{l}\text { - ELFM }{ }^{2} \text { and interim-use phase } \\
\text { - Approach from an environmental perspective }\end{array}$ & \\
\hline & European Union & $\begin{array}{l}\text { - Increased resource independence } \\
\text { - Economically independent }\end{array}$ & \\
\hline & Local Government & $\begin{array}{l}\text { - Close communication with operators } \\
\text { - Environmental motivation }\end{array}$ & \\
\hline Scientific Actors & Researcher & $\begin{array}{l}\text { - Focus on low discharge flow and env. benefits } \\
\text { - Risky recycling activity }\end{array}$ & \\
\hline \multirow[t]{3}{*}{ Business Actors } & Operators & $\begin{array}{l}\text { The primary objective is recuperation of land, } \\
\text { energy, and materials } \\
\text { - Stakeholder involvement is essential for ELFM }\end{array}$ & \\
\hline & Technology Providers & $\begin{array}{l}\text { Environmental clean-up activity using advan- } \\
\text { ced technology } \\
\text { Thermal treatment is needed to avoid new di- } \\
\text { sposal costs (end-of-pipe solution) }\end{array}$ & \\
\hline & Technology incubator & $\begin{array}{l}\text { - Focus on maximizing valorization of materials } \\
\text { - Land recuperation as a secondary objective }\end{array}$ & \\
\hline
\end{tabular}

perceived similarly amongst stakeholders, the economic dimension has a different significance for different stakeholders within the sustainability framework. While most participants emphasized environmental aspects, institutions and operators focused on economic factors with environmental and social "spillovers". Environmental benefits are generally perceived through the reduction of risks through waste removal and the mitigation of primary resource production, whereas risks were described as being similar to those coming from operating landfills. The biggest societal challenge was considered the involvement of all stakeholders.

Operators and institutions both mentioned land-recuperation as the clear primary economic driver of ELFM. The industrial participants also stressed the driving force of "doing activities" in the form of large-scale pilot projects. One participant stated that "when we start mining the Remo site, from this one activity, many spin-offs will develop". They further emphasized the economic advantages of technological development in cost reductions. In agreement with the scientific participant and the technology incubator, operators are favoring the idea of combining public and private money for investment support. This could take the form of private-public partnerships, subsidies or public insurances. While institutional actors were not as fond of this idea, they perceived a driver in cost reductions for long-term monitoring through ELFM and an interim usephase. Local communities identified the generation of employment, especially of low-skilled labor, as well as energy generation and material recovery as main drivers for ELFM. External factors, like market prices for primary and secondary raw material, could be driving ELFM projects, if rising but also hinder development if decreasing. Similarly, operators stated that technological development, generally perceived as a driver, could also be a barrier to investment if new technologies emerge before the planned return on investment. Institutions and operators described finding investors in general as one of the most difficult challenges for ELFM. This is explained partly by a lack of awareness in the relevant sectors and partly by (un)known risks in the development of market prices, new technologies and public acceptance: "You get investment support a bit here, a bit there. So, you have to puzzle all these small supports for your big investment, and this is, of course, time-consuming." Operators emphasized that high monitoring and sampling activities would drive up costs and could hinder implementation. Site-specific factors, like the location of the landfill and waste composition, could also be a relevant barrier or driver, depending on the context. Table 4 gives a more detailed overview of the economic perceptions about ELFM.

While most environmental benefits are perceived through the mitigation of risks, technology providers further mentioned that technological development could lead to improvements in future landfilling and recycling operations, and thereby have indirect environmental benefits. The main risks perceived were odor, noise, and risks for human health coming from dust or groundwater contamination. Formerly uncontrolled dumped waste could pose risks to ELFM operations when discovered and toxic materials could be brought back into the material cycles. Institutional and local community members also expressed their concerns about auto-combustion of gases initiated by the change of anaerobic to aerobic conditions in landfills. Additionally, the scientist believes bad execution could lead to bigger environmental problems than before: "These are huge risks, also on the environmental level the risk of creating a bigger environmental problem than before is still there." Operators also mentioned that the energy consumption of ELFM activities today is mainly fossil fuel based. Table 5 shows the main environmental risks and benefits according to the different stakeholder groups.

Stakeholder involvement, perceived as the biggest societal challenge, could affect ELFM implementation in va- 
TABLE 4: Table 4 summarizes the Economic Drivers and Barriers.

\begin{tabular}{|c|c|c|c|}
\hline \multirow{2}{*}{$\mathrm{QH} /$ value chain-Class } & \multirow{2}{*}{ Stakeholder } & \multicolumn{2}{|c|}{ Economic Drivers and Barriers } \\
\hline & & Specific Beliefs & Common Beliefs \\
\hline Community members & De Locals & $\begin{array}{l}\text { - Material recovery and job generation } \\
\text { - Long-term project costs }\end{array}$ & \multirow{8}{*}{$\begin{array}{l}\text { Changes in market prices for primary and sec- } \\
\text { ondary raw materials affect the economic fea- } \\
\text { sibility of ELFM } \\
\text { - Location of the landfill and waste composition } \\
\text { can be a driver or a barrier }\end{array}$} \\
\hline \multirow[t]{3}{*}{ Institutional Actors } & Waste Agency & $\begin{array}{l}\text { - Avoidance of long-term monitoring costs } \\
\text { - Interim use of landfill can reduce costs } \\
\text { - Lack of knowledge with investors is a barrier }\end{array}$ & \\
\hline & European Union & - ELFM should be driven by private businesses & \\
\hline & Local Government & - Industrial symbiosis is needed & \\
\hline Scientific Actors & Researcher & $\begin{array}{l}\text { - Emphasis on environmental aspects } \\
\text { - Public financial support is important }\end{array}$ & \\
\hline \multirow[t]{3}{*}{ Business Actors } & Operators & $\begin{array}{l}\text { - Business activity with environmental benefits } \\
\text { Technological uncertainty can hinder in- } \\
\text { vestments } \\
\text { Lack of public financial support for pilot } \\
\text { projects }\end{array}$ & \\
\hline & Technology Provider & $\begin{array}{l}\text { - Profitability of ELFM is in question } \\
\text { - Sorting technology is not efficient enough } \\
\text { - Financial uncertainty poses a long-term risk }\end{array}$ & \\
\hline & Technology incubator & $\begin{array}{l}\text { Hydrogen production could be an essential } \\
\text { driver } \\
\text { - The flexibility of outputs ca drive ELFM } \\
\text { - Material recovery is a long-term driver }\end{array}$ & \\
\hline
\end{tabular}

TABLE 5: Table 5 Summarizes Environmental Benefits and Risks.

\begin{tabular}{|c|c|c|c|}
\hline \multirow{2}{*}{ QH/value chain-Class } & \multirow{2}{*}{ Stakeholder } & \multicolumn{2}{|c|}{ Environmental Benefits and Risks } \\
\hline & & Specific Beliefs & Common Beliefs \\
\hline Community members & De Locals & $\begin{array}{l}\text { Risks of toxic materials being reintroduced } \\
\text { into the material cycle } \\
\text { Risks for natural habitat on top of old landfills }\end{array}$ & \multirow{8}{*}{$\begin{array}{l}\text { - Reduction of risks through waste removal and } \\
\text { avoidance of primary resource consumption } \\
\text { - Mitigation of groundwater pollution and soil } \\
\text { - Risks of ELFM are similar to current/traditional } \\
\text { landfilling operations } \\
\text { - Risks for odor, noise and human health }\end{array}$} \\
\hline \multirow[t]{3}{*}{ Institutional Actors } & Waste Agency & - The risk for auto combustion of gases & \\
\hline & European Union & $\begin{array}{l}\text { Environmental benefits on global level } \\
\text { Recuperation of construction materials is } \\
\text { important env. factor }\end{array}$ & \\
\hline & Local Government & & \\
\hline Scientific Actors & Researcher & - High operational risks & \\
\hline \multirow[t]{3}{*}{ Business Actors } & Operators & - Risks for air and groundwater pollution & \\
\hline & Technology Provider & $\begin{array}{l}\text { Uncertainty about long-term environmental } \\
\text { impacts } \\
\text { ELFM in combination with CCS can improve } \\
\text { environmental performance }\end{array}$ & \\
\hline & Technology incubator & $\begin{array}{l}\text { Waste composition is a risk } \\
\text { Uncontrolled dumping poses risks }\end{array}$ & \\
\hline
\end{tabular}

rious ways. Operators fear public opposition by non-involvement, but also consider a need for more awareness of ELFM, in general, to make financing and permitting processes easier. All stakeholders identified a lack of public acceptance as a project's biggest societal barrier at this time: "That's the barrier number one." Operators, institutions and local community members explained this partly by knowledge and awareness gaps between the different parties involved, adding to concerns about the environmental risks. According to an institutional participant knowledge distribution should also include public authorities, stating, "[The] most important thing, from my point of view, is the transitioning of the mindsets, that's a policy aspect." Local community members also urged for the inclusion of politicians in this process and criticized the conflict of interest between short-term politics and long-term deve- lopment. The participant from the local government, on the other hand, mentioned the organization of town hall meetings, being not very well visited, and explained that positive change by the operators is often not recognized within the community, while small mistakes are overemphasized. This view is congruent with the beliefs of local community members and operators, who see a barrier in small groups being able to hinder a project through legal procedures, overpowering a "silent" but supportive majority. A situation where "a small group talks for a large community that doesn't talk." In Table 6, an overview of the perceived societal challenges can be found.

\subsubsection{Key Actors of ELFM}

All stakeholders, but the operators themselves, who perceived investors as highly important, named the ope- 
TABLE 6: Table 6 summarizes the Societal Challenges.

\begin{tabular}{|c|c|c|c|}
\hline \multirow{2}{*}{$\mathrm{QH} /$ value chain-Class } & \multirow{2}{*}{ Stakeholder } & \multicolumn{2}{|c|}{ Societal Challenges } \\
\hline & & Specific Beliefs & \multirow{4}{*}{$\begin{array}{l}\text { Common Beliefs } \\
\text { - Public involvement is perceived as the biggest } \\
\text { challenge } \\
\text { Stakeholder involvement perceived as an ad- } \\
\text { vantage for ELFM implementation } \\
\text { Recuperation of land for recreational purposes } \\
\text { can help to get acceptance for ELFM imple- } \\
\text { mentation } \\
\text { General legal framework can hinder ELFM im- } \\
\text { plementation }\end{array}$} \\
\hline Community members & De Locals & $\begin{array}{l}\text { - Fear of environmental impacts } \\
\text { - Supporters of ELFM do not participate as acti- } \\
\text { vely as opponents }\end{array}$ & \\
\hline \multirow[t]{3}{*}{ Institutional Actors } & Waste Agency & $\begin{array}{l}\text { Integration of political actors is necessary } \\
\text { Conflicts of interests between short-term (poli- } \\
\text { tical) projects and long-term development }\end{array}$ & \\
\hline & European Union & $\begin{array}{l}\text { Reuse and recycling is preferred over primary } \\
\text { resource use }\end{array}$ & \\
\hline & Local Government & $\begin{array}{l}\text { - Complaints are often subjective } \\
\text { - Positive change is rarely recognized } \\
\text { tizens }\end{array}$ & \\
\hline Scientific Actors & Researcher & & \\
\hline \multirow[t]{3}{*}{ Business Actors } & Operators & $\begin{array}{l}\text { - Fear of public opposition } \\
\text { - Regulations for non-ELFM production } \\
\text { - Need for more awareness about ELFM in gene- } \\
\text { ral public and investors }\end{array}$ & \\
\hline & Technology Providers & $\begin{array}{l}\text { - Societal and environmental pressures differ in } \\
\text { location }\end{array}$ & \\
\hline & Technology incubator & $\begin{array}{l}\text { Regulatory instruments are needed for ELFM } \\
\text { implementation }\end{array}$ & \\
\hline
\end{tabular}

rating company as the most important key actor involved. Regulatory bodies should play a crucial role according to all stakeholders. The institutional and scientific side also stressed the importance of involving local communities. However, Institutions perceive the general public as even more important than local residents. Scientific bodies are mostly perceived as platforms for knowledge transfer between the involved parties but would play a secondary role in the realization of ELFM projects. Technology providers emphasized their own role by stressing needs for optimizing sorting technologies.

All stakeholders perceived the role of institutions as an overall positive. Most participants named the Flemish waste agency one of the key actors involved and were overall satisfied with their role. The subsidiarity principle of the EU was positively acknowledged by institutional participants, who also perceived their regional role as a platform for experimentation and trials. It was criticized by communal, scientific and institutional participants that advice from regulatory bodies is often not followed on a political level. Similarly, technology providers and the technology incubator, institutional participants and operators would appreciate regulations that "help and stimulate landfill mining activities" and make them easier to monitor, but could not identify any current regulations "hampering" ELFM implementation.

\subsection{Stakeholder Archetypes}

To structure the diverse and complex perspectives, stakeholder archetypes were developed. Each stakeholder type ought to be understood as a prototype for a distinct approach to ELFM implementation to facilitate the understanding of different stakeholders, and tailor research and industrial activities to stakeholder needs. In total five different stakeholder archetypes have emerged from the analysis: The Engaged Citizen, the Entrepreneur, the
Technology Enthusiast, the Visionary and the Skeptic. If certain concepts in one coding category were interlinked with a dominant stakeholder class, they were grouped to represent a district archetype. Some archetypes share common beliefs, as overlapping coding was applied, but a new type was developed when a distinct property or belief differed substantially from other combinations or concepts were contradicting each other.

\subsubsection{The Engaged Citizen}

The Engaged Citizen approaches ELFM from an environmental perspective. Her or his main concerns are the safety and well-being of their community. The avoidance of odor, noise, and traffic, as well as the mitigation of environmental risks affecting human health, are a main priority. To achieve influence on a project, Engaged Citizens actively participate in the implementation process and seek to gain and distribute information. While their influence on a specific ELFM project can be quite high, their overall impact on ELFM implementation as an industrial sector is rather low. Engaged Citizens organize in a non-governmental form but have access to various resources due to the diversity of their group. A rather risk-averse attitude in combination with a curiosity for technology and innovation drive them. Because of their environmental approach to ELFM, financing models are considered less important. Problems often occur in communication with other stakeholders and are related to knowledge gaps about technologies, regulations and project details. Yet, through engagement, the Engaged Citizen gains information and establish a moderate knowledge base.

\subsubsection{The Entrepreneur}

The Entrepreneur approaches ELFM from a private economic perspective. While a profitable business is a primary concern, environmental and societal factors of a 
project are also important. Land recuperation and energy generation are seen as main drivers by Entrepreneurs, while uncertainties add to their hurdles. These include waste compositions, investment support, and regulations. The Entrepreneur can highly influence a specific ELFM project as they are usually part of a private business along the value-creation-chain of ELFM. Her or his overall impact on ELFM implantation can be considered moderate to high but depends on the interconnectedness with other stakeholders. Entrepreneurs present a willingness to take risks and a high knowledge base about ELFM processes. Because of the presumed environmental benefits of ELFM, they expect public financial support for ELFM implementation.

\subsubsection{The Technology Enthusiast}

Technology Enthusiasts approach ELFM from an innovative perspective. The development of new technologies is seen as the main driver of ELFM implementation. While the Technology Enthusiast clearly sees a need for private economic profitability of ELFM, her or his true motivations to engage lay in creating environmental benefits through technology. Combining thermal treatment of waste streams with carbon capture and storage (CCS) technology, for example. Technology Enthusiasts emphasize the potential for hydrogen production of ELFM and see a need for revising waste management regulations to emphasize the storage function of landfills. They take a long-term view on ELFM implementation and are willing to take financial risks. Since the Technology Enthusiast is usually, but not necessarily, engaged in ELFM projects along the value-creation-chain, she or he favors public financial support similarly to Entrepreneurs. Due to their engagement, Technology Enthusiasts provide a high knowledge base on ELFM processes, but often have difficulties understanding the needs of local communities or policymakers.

\subsubsection{The Visionary}

The Visionary approaches ELFM from a societal perspective. She or he believes that societal change is necessary for gaining environmental benefits. ELFM can function as a vehicle for this change, which is driven by technological development. The mitigation of future and long-term environmental burdens motivates a Visionary's engagement. Visionaries are usually part of a governmental institution and involved in policymaking. For them, strategic advantages through increased resource independence play a crucial role in ELFM. While their influence on specific ELFM projects is low, their impact on ELFM implementation is high. From a Visionary's point of view, ELFM could very well be implemented as a public activity, given the environmental and societal benefits are sufficient. She or he considers the general public rather than local communities. This emphasizes the importance of environmental risk mitigation for Visionaries. They have a high knowledge base about environmental and societal aspects of EFLM but lack knowledge of technical processes and projectspecific needs.

\subsubsection{The Skeptic}

Skeptics approach ELFM mainly from an environmental perspective but are convinced ELFM needs to be feasible as a private economic activity to achieve brought implementation. Focusing on risks, A Skeptic tends to create a self-enforcing perspective and develop a rather risk-averse attitude. She or he expects ELFM implementation to take its time. Being part of a governmental or research institution, Skeptics see a need for investigating the implications of ELFM implementation and its relations with other industry sectors to add to their high and sometimes very specific knowledge-base. Their influence on a specific ELFM project can be moderate to high but overall impact on ELFM implementation is rather moderate to low.

\section{DISCUSSION}

While it is important to discover the different approaches of stakeholders, their perspectives must be put into context. The main concepts expressed are contrasted to former research findings on the Remo case. This comparative approach should provide new information explaining the justifications of beliefs and knowledge gaps across stakeholders. The first part of the discussion, Perceptions about the Remo landfill, is limited to a comparison with former research about the case. The second part, Implications for ELFM implementation, takes a more general view on ELFM and explains how implementation could differ when applying different perspectives. The last subsection, Implications for future research, gives an outlook about the direction of future ELFM assessment. The latter two subsections also explain how the stakeholder archetypes can be made applicable.

\subsection{Perceptions about the Remo landfill}

Looking at the waste composition at the Remo site, research indicates that beliefs by community members about toxic materials are not justified (cf. Quaghebeur et al. 2013). Danthurebandara et al. (2015a) even show that impacts from ELFM operations on human toxicity can be beneficial. However, in contrast to environmental burdens the impact category was insignificant (Danthurebandara et al., 2015b). Modern landfills are generally perceived as safe and even conditions of older landfills as being better than expected. But, as the waste composition is uncertain and can vary dramatically within one landfill site, sampling becomes either less effective or cost intensive (Quaghebeur et al., 2013). These circumstances, in combination with incomplete records and illegal dumping of waste, put beliefs about the safety of landfills generally into question. Nonetheless, at the beginning of the 20th century, about $80 \%$ of MSW consisted of ashes from residential heating and inert or easily degradable materials (Van Passel et al., 2013).

Land reclamation, material, and energy recuperation are considered to be the main revenue streams for ELFM operations at the Remo site. Especially community members perceived material recovery as a major driver for ELFM operations. This is questionable. The Remo landfill lays within a natural habitat where the land price is rather low. Van Passel et al. (2013) identify land reclamation to constitute a relatively low benefit and note that government incentives for renewable energy make up a major portion 
of the WtE revenue stream. They show the three most important impacts on ELFM's private economic performance are (i) WtE efficiency, (ii) electricity- and (iii) $\mathrm{CO}_{2}$-price. This claim is supported by Danthurebandara et al. (2015b), who identify the plasma gasification process as a major economic impact and its efficiency as the main factor affecting the profitability of ELFM at the Remo site. This again shows the importance of changing market conditions, which all stakeholders perceived as one of the biggest challenges for ELFM implementation.

Danthurebandara et al. (2015a) also support the stakeholders' beliefs that high investment costs are a main barrier for implementation and identify investments in WtE technology as a major cost component. While technological development would push ELFM it could also hinder investments by raising uncertainty.

Some environmental benefits of ELFM have been assessed by Van Passel et al. (2013) and Danthurebandara et al. (2015a). Van Passel et al. (2013) conclude that benefits from a reduction in greenhouse gases through material recovery have the biggest impact. This contrasts with Danthurebandara et al. (2015a), who identify an environmental burden in the impact category Climate Change, and most benefits in the impact categories Fossil Depletion, Ionizing Radiation and Urban Land Occupation. The differences in GHG emissions is explained by distinct approaches: Van Passel et al. (2013) consider a longer methane recovery and purchasing materials and energy on the market for the do-nothing scenario (Danthurebandara et al. 2015a). Danthurebandara et al. (2015a) show all impact categories have beneficial effects but were not significant, other than the impact categories climate change and ozone depletion.

A topic mostly neglected by the stakeholders is biodiversity. Although impacts on biodiversity through ELFM are positive due to land reclamation, temporal burdens on biodiversity can occur during the time of operation (De Vocht et al., 2011). Overall, aiming at $75 \%$ open landscape after operations could lead to the restoration of 162 ha of Flemish heathland, representing $1.17 \%-1.75 \%$ in relative terms. Additionally, disturbance trough illumination, noise or transport can affect biodiversity negatively, however, covered WtE and WtM installations could help to minimize the risk. Impacts on the aquatic system are expected to be minimal, as the Remo site is situated above the groundwater level (De Vocht et al., 2011).

The belief that public involvement is one of the biggest societal challenges is well manifested within stakeholders. This is reasonable, regarding the Remo case, as public opposition has led to delays. Yet, this belief cannot be transferred to ELFM in general. The general perception of ELFM was described as positive even within opposing groups to the Remo site. Stakeholder involvement and communication were highlighted by several participants and therefore contradicts the belief about communication problems amongst stakeholders.

\subsection{Implications for ELFM Implementation}

Another societal challenge was not mentioned explicitly but can be derived implicitly from the interviews: Different stakeholders approach ELFM with different motiva- tions. Should ELFM be implemented primarily as a clean-up activity or as a business activity? Depending on which point of view one takes, different implications come to light. As a clean-up activity, ELFM would be mostly done by governmental institutions and resource and energy recovery would have a cost-reducing objective. As a business activity, ELFM would be profit-driven, where conflicting goals can lead to trade-offs with its environmental performance. Of course, inner-dimensional trade-offs between environmental impact categories still have to be considered, even without motivations for profit maximization. A mixed approach could lead to cherry-picking by industrial actors and higher societal costs at the end, as cross-financing of less profitable projects becomes more difficult.

All stakeholders have a positive attitude towards ELFM. This is not very surprising considering their active involvement at the Remo site. Still, this attitude is also in line with the European strategy to transfer into a circular economy and reduce burdens from carbon dioxide (EC, 2015; UN, 2016). Even community members opposing the Remo case were not considered to be against ELFM in general, but opposition is rather linked to specific issues and ongoing landfilling operations (Internetgazet et al., 2018). The stakeholder archetypes can enhance the understanding between different ELFM practitioners. This can increase awareness about ELFM and help anticipate public opposition by integrating different perspectives. Policymakers can gain insights on important matters regarding ELFM implementation and avoid future conflicts without having to do time-consuming, and costly research on a project.

Another challenge for ELFM implementation lays in current and future regulations. Interestingly, landfills are in general perceived as temporary storage facilities by all stakeholders. This might be explained through their involvement in a specific ELFM case, and thus, a higher awareness for other perspectives. Technology providers preferring landfilling over incineration in contrast to the waste disposal hierarchy, supports the view of landfills as storage facilities, similarly to Van Passel et al. (2013). The development of ELFM puts this waste disposal hierarchy into question. As new technologies might emerge, higher benefits could be possible, when also landfilling current waste streams and processing, i.e. mining, them later on. In this context, landfill taxes can play a crucial role. In research these are mostly considered to be costs, taking a private economic perspective (Johansson et al., 2013; Winterstetter et al., 2015). The implied societal benefits (tax revenues) are usually not considered. Moreover, it is often unclear if these taxes have to payed or if exemption of landfill taxes would be granted, raising uncertainty about future outcomes. In Sweden and Austria, exemptions are possible but also depends on the composition and age of the redeposited waste (Hermann et al., 2014; Johansson et al., 2012). On the other hand, the exemption from taxes always implies a societal cost, that has to be considered. Hoogmartens et al., (2016) show, for example, that welfare maximization, through the combination of Enhanced Waste Management and optimal taxation, is possible. However, they focus on current waste streams and more research is needed. 


\subsection{Implications for Future Research}

When considering implications for future ELFM research, especially from a societal perspective, it becomes evident that more work is needed. To derive implications for regulatory changes and to better understand the real potential of ELFM, it is important to take a holistic, industrial perspective into account. Estimating the resource potential of ELFM for Europe, for example, is a necessary next step, but not easy to achieve. Yet, it could help justify or deny public support and help design optimal monetary control and management tools to foster a sensible ELFM implementation. This research should be integrated to make interdimensional trade-offs visible.

Considering the private economic dimension of ELFM, the analysis shows that hidden private costs for stakeholder involvement, for example, have not been taken into account. Commonly, only operational and capital costs (e.g for transport, facilities or personnel costs) are assessed (Danthurebandara et al., 2015a; Frändegård et al., 2015; Kieckhäfer et al., 2017; van der Zee et al., 2004; Wolfsberger et al., 2016; Zhou et al., 2014). Additionally, time effects should be considered when building investment and cost models. While discounting is usually applied when assessing a project's net present value (NPV) (Hermann et al., 2016a; Van Passel et al., 2013; Winterstetter et al., 2018), delays through social resistance or permitting processes are not considered.

The main environmental benefits are believed to come from the mitigation of risk through waste removal. To put those beliefs into context, it is important to identify longterm risks of landfills, but this challenge still has to be taken on (Sauve and Van Acker, 2018). Waste composition, depending on factors like location, regulations or the time period of landfilling, plays a crucial role in determining these long-term environmental impacts (Quaghebeur et al., 2013). Institutions share this point of view, showing awareness for monitoring activities exceeding the obligatory 30 years aftercare period. Environmental impacts of ELFM operations are comparable to traditional landfilling. Since ELFM operations are expected to go on over a timeframe of 10 to 20 years, and environmental impacts of landfills would accumulate over time, the assumption can be made that there are environmental benefits from mitigating longterm environmental risks through ELFM. The extent of these benefits is still difficult to assess, making an economic evaluation of externalities for ELFM ambitious.

The societal dimension of sustainability is usually assessed through the monetization of environmental impacts, if at all (Damigos et al., 2015; Marella and Raga, 2014; Van Passel et al., 2013; Winterstetter et al., 2018, 2015). Fewer studies tackle societal impacts through nonmonetary assessment (Hermann et al., 2016b; Pastre et al., 2018). Monetizing environmental impacts is problematic because impacts are chosen selectively and often do not represent a holistic picture. Non-monetary societal impacts are often left out, due to their subjectivity. If integrated, their validity is in question, specifically because of their subjective character. The developed archetypes can help to integrate different subjective approaches rather than creating a seeming objectivity through monetization. One option could be developing different weighing factors from the archetypes to integrate them into ELFM assessment methods. This way, the effect of different perspectives on societal impacts could be made visible and enhance the discussion on social burdens and benefits. The archetypes could be used in an educational context and help to understand inner- and interdimensional trade-offs better when assessing the sustainability of ELFM projects.

Regional differences should be taken into account when assessing ELFM. Damigos et al (2015) conduct a contingent valuation survey in Greece to determine and monetize stakeholder values. In contrast to the interviewees, the participants of the survey value job creation (70\%) as their main incentive to engage in LFM operations only followed by environmental benefits (22.4\%). Survey participants recognize water, soil, and air pollution as the biggest operational risks of landfilling, from which perceptions about perceived risks of ELFM operations can be derived. About $60 \%$ of survey participants valued WtE and WtM benefits as most important, whereas approximately $20 \%$ of participants valued the avoidance of environmental burdens, and equally landfill space reclamation, as very important (Damigos et al., 2015). These beliefs have to be further assessed. While it has been shown that WtE plays a crucial role in gaining private economic benefits from ELFM, WtM streams have proven less profitable (Van Passel et al. 2013; Danthurebandara et al. 2015a). Societal benefits and their monetization, however, need more scientific attention.

\section{CONCLUSIONS}

Landfills were perceived as temporary storage facilities and knowledge about ELFM was mostly well established. All stakeholders constitute a positive attitude towards ELFM, but motivations for engagement differ amongst stakeholders. Misconceptions exist about the main economic drivers for ELFM implementation, where industry and institutional actors identify land recuperation and communal actors material recovery as main drivers. Homogenously, stakeholders identified environmental benefits coming from the mitigation of risks through waste removal and avoidance of primary resource consumption. Stakeholder integration was perceived as the main societal challenge.

The fife stakeholder archetypes, namely the Engaged Citizen, the Entrepreneur, the Technology Enthusiast, the Visionary, and the Skeptic, outline the main perspectives to be taken on ELFM implementation. They convey major differences in approaching ELFM and new technological concepts alike and serve as a tool for ELFM practitioners and researchers, who seek a better understanding of the parties involved. Moreover, they can be used for educational purposes to enhance understanding of sustainability issues. They make inner- and interdimensional conflicts of sustainability visible and help understand the societal side of ELFM.

It is important to note that implementing ELFM at industrial scale and scope depends on its main purpose. If ELFM is primarily done as a business activity aiming for profitability, in contrast to a clean-up activity, different regu- 
latory changes become necessary. A wide range of policy instruments including taxation, subsidies, public-private partnerships, investment support and more, have to be carefully analyzed and tested. This implies the need for new models in ELFM assessment integrating all dimensions of sustainability in a comprehensive and comparable manner.

Future research has to refine the private economic and environmental assessment, taking hidden costs and benefits and dynamic time effects into account. Special focus should be given to the societal dimension, which lacks a thorough assessment in ELFM research.

\section{ACKNOWLEDGMENTS}

This project has received funding from the European Union's EU Framework Programme for Research and Innovation Horizon 2020 under Grant Agreement No 721185.

Part of the research was presented at the 4th International Symposium on Enhanced Landfill Mining 2018 in Mechelen, Belgium.

The authors would like to thank all interviewees for their participation and openness.

\section{REFERENCES}

Amjahid, M., Raether, E., 2018. Leicht entzündlich [WWW Document]. Zeit Online. URL https://www.zeit.de/2018/48/gilets-jaunesfrankreich-proteste-spritpreise-bewegung-wut-warnweste

Arnkil, R., Järvensivu, A., Koski, P., Piirainen, T., 2010. Exploring Quadruple Helix: Outlining user-oriented innovation models, Tampere: The CLIQ.

Ballard, M., Becherer, J., Coeymans, K., De Block, E., De Bruyn, G., De Coster, L., De Schutter, J., Lemmens, J., Philipsen, L., Schroeyers, F., Timmers, H., Vandebeek, G., Vanhemel, P., Vannuffelen, G., 2018. A Locals' Perspective Towards Social Acceptance of the Closingthe-circle Project in Houthalen-Helchteren, in: 4th International Symposium on Enhanced Landfill Mining. pp. 353-358.

Bosmans, A., Vanderreydt, I., Geysen, D., Helsen, L., 2013. The crucial role of Waste-to-Energy technologies in enhanced landfill mining: A technology review. J. Clean. Prod., Special Volume: Urban and Landfill Mining 55, 10-23. https://doi.org/10.1016/j.jclepro.2012.05.032

Corbin, J., Strauss, A., 1990. Grounded Theory Research: Procesures, Canons and Evaluative Criteria. Zeitschrift fuer Soziologie 19, 418-427. https://doi.org/http://dx.doi.org/10.1007/BF00988593

Damigos, D., Menegaki, M., Kaliampakos, D., 2015. Monetizing the social benefits of landfill mining: Evidence from a Contingent Valuation survey in a rural area in Greece. Waste Manag. 51, 119-129. https://doi.org/10.1016/j.wasman.2015.12.012

Danthurebandara, M., Van Passel, S., Van Acker, K., 2013. Life Cycle Analysis of Enhanced Landfill Mining: Case Study for the Remo Landfill 1-23. https://doi.org/10.13140/RG.2.1.4576.9763

Danthurebandara, M., Van Passel, S., Van Acker, K., 2015a. Environmental and economic assessment of 'open waste dump' mining in Sri Lanka. Resour. Conserv. Recycl. 102, 67-79. https://doi. org/10.1016/j.resconrec.2015.07.004

Danthurebandara, M., Van Passel, S., Vanderreydt, I., Van Acker, K. $2015 \mathrm{~b}$. Assessment of environmental and economic feasibility of Enhanced Landfill Mining. Waste Manag., Urban Mining 45, 434447. https://doi.org/10.1016/j.wasman.2015.01.041

Danthurebandara, M., Van Passel, S., Vanderreydt, I., Van Acker, K., 2015c. Environmental and economic performance of plasma gasification in Enhanced Landfill Mining. Waste Manag., Urban Mining 45, 458-467. https://doi.org/10.1016/j.wasman.2015.06.022

De Vocht, P., Descamps, S., De Vocht, A.J.P., Descamps, S., 2011. Biodiversity and Enhanced Landfill Mining: Weighting local and global impacts? Int. Acad. Symp. Enhanc. Landfill Min. 275-290. https:// doi.org/10.13140/2.1.4969.8245

EC, 2015. Closing the loop - An EU action plan for the Circular Economy.

EC, 1999. COUNCIL DIRECTIVE 1999/31/EC of 26 April 1999 on the landfill of waste.
Frändegård, P., Krook, J., Svensson, N., 2015. Integrating remediation and resource recovery: On the economic conditions of landfill mining. Waste Manag. 42, 137-147. https://doi.org/10.1016/j.wasman.2015.04.008

Geysen, D., 2017. Enhanced Landfill Mining am Beispiel der Deponie Remo in Belgien. Resour. Abfall, Rohstoff, Energ. 30, 515-535.

Group Machiels, 2018. Closing the Circle Project [WWW Document] URL https://machiels.com/en/division/europe/environmental-services/closing-the-circle-project/ (accessed 7.22.18).

Gusca, J., Fainzilbergs, M., Muizniece, I., 2015. Life Cycle Assessment of Landfill Mining Project. Energy Procedia, International Scientific Conference "Environmental and Climate Technologies, CONECT 2014 72, 322-328. https://doi.org/10.1016/j.egypro.2015.06.047

Hermann, R., Baumgartner, R.J., Sarc, R., Ragossnig, A., Wolfsberger, T., Eisenberger, M., Budischowsky, A., Pomberger, R., 2014. Landfill mining in Austria: Foundations for an integrated ecological and economic assessment. Waste Manag. Res. 32, 48-58. https://doi. org/10.1177/0734242X14541168

Hermann, R., Baumgartner, R.J., Vorbach, S., Wolfsberger, T., Ragossnig, A., Pomberger, R., 2016a. Holistic assessment of a landfill mining pilot project in Austria: Methodology and application. Waste Manag. Res. 34, 646-657. https://doi.org/10.1177/0734242X16644517

Hermann, R., Wolfsberger, T., Pomberger, R., Sarc, R., 2016b. Landfill mining: Developing a comprehensive assessment method. Waste Manag. Res. 34, 1157-1163. https://doi. org/10.1177/0734242X16657610

Hoogmartens, R., Eyckmans, J., Van Passel, S., 2016. Landfill taxes and Enhanced Waste Management: Combining valuable practices with respect to future waste streams. Waste Manag., SI:Sanitary Landfilling 55, 345-354. https://doi.org/10.1016/j.wasman.2016.03.052

Internetgazet, Lingier, J., Internetgazet, 2018. "Stinkbom" Remo staat op springen [WWW Document]. URL http://www.internetgazet.be/ houthalen-helchteren/stinkbom-remo-staat-op-springen.aspx (accessed 7.22.18)

Jain, P., Powell, J.T., Smith, J.L., Townsend, T.G., Tolaymat, T., 2014. Life-Cycle Inventory and Impact Evaluation of Mining Municipal Solid Waste Landfills. Environ. Sci. Technol. 48, 2920-2927. https://doi. org/10.1021/es404382s

Johansson, N., 2016. Landfill mining: Institutional challenges for the implementation of resource extraction from waste deposits. https://doi.org/10.3384/diss.diva-132424

Johansson, N., Krook, J., Eklund, M., 2012. Transforming dumps into gold mines. Experiences from Swedish case studies. Environ. Innov. Soc. Transitions 5, 33-48. https://doi.org/10.1016/j. eist.2012.10.004

Johansson, N., Krook, J., Eklund, M., Berglund, B., 2013. An integrated review of concepts and initiatives for mining the technosphere: towards a new taxonomy. J. Clean. Prod., Special Volume: Urban and Landfill Mining 55, 35-44. https://doi.org/10.1016/j.jclepro.2012.04.007

Jones, P.T., Geysen, D., Tielemans, Y., Van Passel, S., Pontikes, Y., Blanpain, B., Quaghebeur, M., Hoekstra, N., 2013. Enhanced Landfill Mining in view of multiple resource recovery: a critical review. J. Clean. Prod., Special Volume: Urban and Landfill Mining 55, 45-55. https://doi.org/10.1016/j.jclepro.2012.05.021

Kieckhäfer, K., Breitenstein, A., Spengler, T.S., 2017. Material flow-based economic assessment of landfill mining processes. Waste Manag., Special Thematic Issue: Urban Mining and Circular Economy 60, 748-764. https://doi.org/10.1016/j.wasman.2016.06.012

Kolehmainen, J., Irvine, J., Stewart, L., Karacsonyi, Z., Szabó, T., Alarinta, J., Norberg, A., 2016. Quadruple Helix, Innovation and the Knowledge-Based Development: Lessons from Remote, Rural and Less-Favoured Regions. J. Knowl. Econ. 7, 23-42. https://doi. org/10.1007/s13132-015-0289-9

Krook, J., Svensson, N., Eklund, M., 2012. Landfill mining: A critical review of two decades of research. Waste Manag. 32, 513-520. https://doi.org/10.1016/j.wasman.2011.10.015

Krook, J., Svensson, N., Van Acker, K., Van Passel, S., 2018. How to Evaluate (Enhanced) Landfill Mining: A Critical Review of REcent Environmental and Economic Assessments, in: Jones, P.T., Machiels, L. (Eds.), 4th International Symposium on Enhanced Landfill Mining. Mechelen, pp. 317-332.

Laner, D., Cencic, O., Svensson, N., Krook, J., 2016. Quantitative Analysis of Critical Factors for the Climate Impact of Landfill Mining. Environ. Sci. Technol. 50, 6882-6891. https://doi.org/10.1021/acs. est.6b01275 
Lederer, J., Laner, D., Fellner, J., 2014. A framework for the evaluation of anthropogenic resources: The case study of phosphorus stocks in Austria. J. Clean. Prod. 84, 368-381. https://doi.org/10.1016/j. jclepro.2014.05.078

Marella, G., Raga, R., 2014. Use of the Contingent Valuation Method in the assessment of a landfill mining project. Waste Manag. 34, 1199-1205. https://doi.org/10.1016/j.wasman.2014.03.018

Pastre, G., Griffiths, Z., Val, J., Tasiu, A.M., Camacho-Dominguez, E.V., Wagland, S., Coulon, F., 2018. A Decision Support Tool for Enhanced Landfill Mining. Detritus 01, 91-101. https://doi.org/10.26403/ detritus/2018.5

Quaghebeur, M., Laenen, B., Geysen, D., Nielsen, P., Pontikes, Y., Van Gerven, T., Spooren, J., 2013. Characterization of landfilled materials: screening of the enhanced landfill mining potential. J. Clean. Prod., Special Volume: Urban and Landfill Mining 55, 72-83. https://doi.org/10.1016/j.jclepro.2012.06.012

Quaghebeur, M., Laenen, B., Nielsen, P., 2010. Valorisation of materials within Enhanced Landfill Mining: what is feasible? ... Enhanc. Landfill ... 4-6.

Sauve, G., Van Acker, K., 2018. To Mine or not to Mine: A Review of the Effects of Waste Composition, Time and Long-Term Impacts of Landfills in the Decision Making for ELFM, in: Machiels, L., Jones, P.T. (Eds.), 4 Th International Symposium on Enhanced Landfill Mining. Mechelen, pp. 379-385.

Thomas, D.R., 2006. A General Inductive Approach for Analyzing Qualitative Evaluation Data. Am. J. Eval. 27, 237-246. https://doi. org/10.1177/1098214005283748
UN, 2016. Paris Agreement. United Nations, New York.

Van der Zee, D.J., Achterkamp, M.C., de Visser, B.J., 2004. Assessing the market opportunities of landfill mining. Waste Manag. 24, 795-804. https://doi.org/10.1016/j.wasman.2004.05.004

Van Passel, S., Dubois, M., Eyckmans, J., de Gheldere, S., Ang, F., Tom Jones, P., Van Acker, K., 2013. The economics of enhanced landfill mining: Private and societal performance drivers. J. Clean. Prod., Special Volume: Urban and Landfill Mining 55, 92-102. https://doi. org/10.1016/j.jclepro.2012.03.024

Winterstetter, A., Laner, D., Rechberger, H., Fellner, J., 2015. Framework for the evaluation of anthropogenic resources: A landfill mining case study - Resource or reserve? Resour. Conserv. Recycl. 96, 19-30. https://doi.org/10.1016/j.resconrec.2015.01.004

Winterstetter, A., Wille, E., Nagels, P., Fellner, J., 2018. Decision making guidelines for mining historic landfill sites in Flanders. Waste Manag. 77, 225-237. https://doi.org/10.1016/j.wasman.2018.03.049

Wolfsberger, T., Pinkel, M., Polansek, S., Sarc, R., Hermann, R., Pomberger, R., 2016. Landfill mining: Development of a cost simulation model. Waste Manag. Res. 34, 356-367. https://doi. org/10.1177/0734242X16628980

Zhou, C., Fang, W., Xu, W., Cao, A., Wang, R., 2014. Characteristics and the recovery potential of plastic wastes obtained from landfill mining. J. Clean. Prod. 80, 80-86. https://doi.org/10.1016/j.jclepro.2014.05.083

\section{ANNEX A}

The appendix provides the developed interview guide providing the basis for the coding categories used to analyze the data.

\section{Section 1: Approach to Landfills}

Question 1

What is a landfill for you?

Follow up

- Is it a waste management solution, a source of pollution, a resource reservoir or a land occupant?

- Why do you think this is the main function of a landfill?

- How do you think this function is met?

- What other functions does a landfill have?

- For the functions, you just described, what advantages and/or disadvantages can you see?

- While recycling becomes more and more important, why do you think landfills are still needed?

Question 2

Can you, in general, describe what advantages and/or disadvantages having landfills comes with?

Follow up

- Do landfills have an effect on your day-to-day life?

- Do you benefit from landfills? (Who benefits from landfills?)

- How? (get rid of waste, profits, protect society/environment, etc.)

- What factors influence your perception of landfills that are uncertain?

- How safe do you think landfills are?

- Where do you think to lay unforeseeable risks of landfills?

If yes:

- How are landfills managed to keep them safe? (How should landfills be managed to keep them safe?)

- What risks remain by landfilling waste?

- What should change to make landfills even safer?

If no:

- Why do you consider landfills unsafe?

- To whom are landfills unsafe?

- What exactly about landfills do you consider unsafe? (Management, processing, transport, after-(after) care, etc.)

- How could you manage landfills in a safer way?

Question 3

When you think about the REMO site, do you have positive or negative associations?

Follow up

- Can you explain where these associations come from?

- Specific to this landfill, what is its main function to you? 
- What experiences have you made with this landfill and/or its management?

- Are you satisfied with the current management of this landfill?

- What alternative options do you see for the future management of this landfill?

- Which options would you prefer and why?

- Which options would you avoid and why?

\section{Section 2: Involvement in ELFM}

\section{Question 4}

Are you familiar with the concept of LFM/ELFM?

Follow up

- Please describe your idea about LFM/ELFM to me.

- How did you learn about LFM/ELFM?

- How did you get involved with LFM/ELFM?

Question 5

Do you think LFM/ELFM should be done?

Follow up

If yes:

- How should LFM/ELFM be carried out?

- Who should be involved in such a project?

- Why should LFM/ELFM be done?

- Where should LFM/ELFM be done?

If no:

- Why not?

- Do you see risks in leaving a landfill untouched?

- Who do you think is/should be responsible for impacts after 30 years (the after-care period)?

- Who should pay for it?

- How should this issue be handled?

- Who do you think benefits from LFM/ELFM and why?

- Do you see LFM/ELFM as a recycling, mining, business, environmental, protective or risky activity?

Question 6

What projects about LFM/ELFM are you involved with?

Follow up

If any:

- What is your role in these projects?

- Why do you want to be part of this project? What motivates you?

- What impact has your involvement on your life/current situation?

If none:

- Why are you not involved?

- Would you like to get involved?

- How could you get involved?

- If you would get involved, what would your objective be?

- Why would that be your objective?

\section{Section 3: Benefits of ELFM}

Question 7

What are the main advantages/opportunities you see in LFM/ELFM projects?

Follow up

- For whom do you mostly see these advantages/opportunities?

- Do you see mostly economic, environmental or societal opportunities?

- How could these opportunities be reached?

- Where do you see limits to these opportunities?

- What factors influence these advantages/opportunities that are uncertain to you?

- Why do you consider these uncertainties?

- What measures could be taken to reduce these uncertainties?

\section{Question 8}

According to you, which are the main environmental benefits of LFM/ELFM?

Follow up

- What types of environmental benefits exactly do you have in mind? (resource conservation, land use, groundwater safety, smell mitigation, pollution control, etc.)

- Where do you see these different benefits? (On which level? Global, national, regional, local? 
- For whom do you see these benefits? Why?

- How could others also benefit from LFM/ELFM?

- How could benefits be transferred to other levels?

- Are you sure, these benefits can be reached?

- Why are you uncertain/certain about these benefits?

- How could you make sure these benefits are reached?

\section{Section 4: Risks of ELFM}

Question 9

What main disadvantages/risks do you see with the realization of an LFM/ELFM project?

Follow up

- For whom do you mostly see these risks?

Do you see mostly economic, environmental or societal risks/disadvantages?

Why do you consider these to be risks/disadvantages?

Why are you afraid of these risks?

What would minimize these risks?

- What factors influence these disadvantages/risks that are uncertain to you?

- Why do you consider these uncertainties?

- What measures could be taken to reduce these uncertainties?

Question 10

According to you, which are the main negative environmental impacts/risks of LFM/ELFM projects?

Follow up

- Who is affected by these impacts?

- Who is responsible for these impacts?

- How could these impacts be avoided or limited?

- Are you sure, these impacts will occur?

- Why are you uncertain/certain about these impacts?

Who will pay for these impacts? How?

Who should pay for these impacts? How?

\section{Section 5: Challenges for ELFM}

\section{Question 11}

According to you, which are the main challenges for the realization of LFM/ELFM projects?

Follow up

- Are these challenges mostly related to economic, environmental, regulatory, market-related or organizational matters?

- Why do you consider these to be the main challenges?

- How would you address these challenges?

- In your opinion what are factors that influence the feasibility and performance of LFM/ELFM projects most?

- Where do you see uncertainties in these challenges?

- How could these uncertainties be minimized/controlled?

Question 12

What economic drivers and/or barriers can you identify?

Follow up

- How do these drivers/barriers affect (your) LFM/ELFM projects?

- How do these drivers/barriers work? Please explain the mechanisms.

- Who is able to affect these mechanisms?

- Where do uncertainties in these mechanisms remain?

- How could these drivers/barriers be emphasized/regulated/overcome?

- Where do you see economic limits to LFM/ELFM?

Question 13

What regulatory instruments do you know affecting LFM/ELFM projects?

Follow up

- What financial and regulatory instruments do you know driving/hindering development towards LFM/ELFM?

- How do these regulatory instruments work? Please explain the mechanism.

- How do these mechanisms address uncertainty?

- What are the most important aspects?

- What regulations are in place to make LFM/ELFM safer/lower risks/profitable?

- Why?

- What aspects drive LFM/ELFM?

- How? 
- For whom?

- What regulations should be changed to promote LFM/ELFM?

- What aspects hinder LFM/ELFM?

- Why? How?

Question 14

Where do you see markets of the products/outcomes of LFM/ELFM?

Follow up

- In your opinion, is there a need for additional materials and/or energy from LFM/ELFM?

- Where do you see difficulties for the marketing products/outcomes from LFM/ELFM?

- What are the uncertainties affecting these difficulties?

- How could you manage these uncertainties?

- Who are purchasers of these products/outcomes?

- Who are competitors to these products/outcomes?

- Where do you see advantages to competitors?

- Where do you see disadvantages to competitors?

Question 15

What societal challenges do you expect/have you experienced in LFM/ELFM projects?

Follow up

- Why do you consider these societal challenges?

- What did you learn from your experience?

How would you address these challenges?

- What instruments could/should be installed to communicate/educate about LFM/ELFM projects?

- How do you communicate/educate about LFM/ELFM?

- To whom do you communicate about LFM/ELFM?

- With what purpose/intent do you communicate LFM/ELFM

- How should different stakeholders be integrated into LFM/ELFM projects?

Section 6: The Role and responsibilities of Institutions and other ELFM Actors

Question 16

According to you, which are the most influential actors when it comes to the planning and realization of LFM/ELFM projects?

Follow up

- What do you think are these different actors' roles and responsibilities?

- What is your/your institution's role and responsibility in LFM/ELFM projects?

- How do you put this role into practice?

- Who is primarily affected by your role in LFM/ELFM projects?

- Where do you see the need for change in your role in LFM/ELFM projects?

Question 17

Who do you think is/should be responsible for regulating and/or communicating LFM/ELFM?

Follow up

- EU, Federal, Regional, Local?

- Who do you think is deciding right now if LFM/ELFM is done?

- What is their role in this process?

- How should their role be changed/differ from its current state to get better outcomes? For whom?

- Who should decide if LFM/ELFM is done?

Question 18

How do/does the authorities/your institution deal with uncertainties concerning LFM/ELFM projects?

Follow up

- What areas are mostly affected by uncertainties (Economics, environment or society?)

- What regulatory instruments do you know handling uncertainties?

- How do they work? Please explain the mechanism.

- What should be changed about them to get better effects?

Question 19

Are you happy with the role of institutions/authorities when it comes to LFM/ELFM?

Follow up

- What are they doing well?

- Where do you see the need for change?

- What regulations should be changed to make LFM/ELFM safe?

- Why? How? What aspects? 